\title{
Influence of Grade of Parent Concrete on Recycled Aggregate Concrete Made with Pozzolanic Materials
}

\author{
Usha Annaluru, ${ }^{1, *}$, Malasani Potharaju², Kode Venkata Ramesh ${ }^{2}$ \\ ${ }^{1}$ Department of Civil Engineering, GITAM Deemed to be University, India \\ ${ }^{2}$ Department of Civil Engineering, GITAM Deemed to be University, Visakhapatnam, India
}

Received April 19, 2021; Revised July 7, 2021; Accepted July 19, 2021

\begin{abstract}
Cite This Paper in the following Citation Styles
(a): [1] Usha Annaluru, Malasani Potharaju, Kode Venkata Ramesh, "Influence of Grade of Parent Concrete on Recycled Aggregate Concrete Made with Pozzolanic Materials," Civil Engineering and Architecture, Vol. 9, No. 5, pp. 1506 - 1512, 2021. DOI: 10.13189/cea.2021.090522.
\end{abstract}

(b): Usha Annaluru, Malasani Potharaju, Kode Venkata Ramesh (2021). Influence of Grade of Parent Concrete on Recycled Aggregate Concrete Made with Pozzolanic Materials. Civil Engineering and Architecture, 9(5), 1506 - 1512. DOI: $10.13189 /$ cea.2021.090522.

Copyright $\odot 2021$ by authors, all rights reserved. Authors agree that this article remains permanently open access under the terms of the Creative Commons Attribution License 4.0 International License

\begin{abstract}
Reducing, recycling and reuse is becoming a world renowned proverb nowadays. The waste from construction industry is increasing day by day. Two major kinds of waste produced from construction industry are concrete waste and brick waste. The concrete waste produced from different buildings will have different strengths. The purpose of this study is to look into the reuse of concrete waste collected from various buildings in the production of recycled aggregate concrete (RAC). RAC 30 is produced by replacing the natural aggregates with recycled aggregates (RA) derived from granite aggregate concretes GAC30 (RA30), GAC35 (RA35) and GAC40 (RA40) grades of parent concrete. In order to produce sustainable concrete, pozzolanic materials such as fly ash (FA) and silica fume (SF) are used in conjunction with cement at a rate of $20 \%$ and $10 \%$ respectively, in addition to cement. The influence of strength of different grades of parent concrete (GAC) on production of RAC of grade 30 (RAC 30) is studied. The experimental results show that RA derived from parent concrete grades GAC30 (RA 30) can be substituted fully in place of normal aggregate. The use of $20 \% \mathrm{FA}$ and $10 \% \mathrm{SF}$ in place of cement also contributed to the enhanced compressive strength, leading to sustainable concrete in field of architectural construction.
\end{abstract}

Keywords Parent Concrete, Recycled Aggregate Concrete, Fly Ash (FA), Silica Fume (SF), Compressive Strength

\section{Introduction}

The use of recycled aggregates in the industry of concrete and the management of construction waste is certainly a significant step in sustainable development. Construction waste accounted for nearly half of the solid waste generated globally. They have an environmental impact at every stage, including raw material extraction, processing, manufacturing, haulage, construction, and final disposal.

Recycled aggregates are generally obtained from buildings, roads, bridges, and sometimes even from catastrophes, such as earthquakes. Aggregates compensate 60 to 80 percent of a concrete mix, so they must be carefully chosen to be long-lasting, blended for maximum efficiency, and monitored to ensure consistent concrete strength and workability.

The main objective of this research is to achieve the target strength in recycled aggregate concrete (RAC) of mix RAC30 using $100 \%$ recycled coarse aggregates with the use of pozzalonic materials partially in place of cement.

Jiake Zhang [1] investigated the effects of carbonation on the performance of recycled concrete aggregates and discovered that carbonated RCA mortars had a greater compressive strength than uncarbonated RCA mortars. Mmasetlhomo Tommy Gumede [2] concluded that the concrete with increased RCA replacement levels produces lesser compressive strength than concrete of low RCA percentages. T. Manikandan [3] concluded that RA has a 
lower density and a greater capacity for absorption than natural aggregates, which he attributed to the adhered mortar's lower density. Sudhir P. Patil [4] studied three types of aggregates: natural coarse aggregate, natural fine aggregate, and RCA. It is found that the target strength was not achieved in RAC for lack of treatment process. Valeria Corinaldesi [5] investigated the effect of mineral additions on the compressive strength of 100 percent RAC and came to the conclusion that it could be improved. Shi Cong Kou [6] looked into the effect of FA as a cement additive on the hardened properties of RAC and found that as the compressive strength of the RAC mix increased, the drying shrinkage of the RAC mix decreased. Shi Cong Kou [7] investigated the effect of FA as a cement addition on the hardened properties of RAC and found that adding FA reduced drying shrinkage and improved resistance to chloride ion penetration. Valeria Corinaldesi [8] studied the mechanical properties and elastic behavior of concrete mixtures made from recycled coarse aggregate concrete and reached the conclusion that if finer recycled coarse concrete aggregate is introduced to the mixture, lower strains could be identified notably for earlier curing time.

Walid Fouad Edris et al. [9] investigated the mechanical properties of translucent concrete using plexiglass bars and fiberglass. The authors concluded that the composite does not harm the mechanical specifications compared with the conventional mortar. New features of concrete with an emphasis on consistency to the requirements of environmental sustainability in the field of architectural construction were obtained. Roz-Ud-Din Nassar et al. [10] investigated the Characteristics of Crushed Stone Sand as Fine Aggregate in Recycled Aggregate Concrete. The findings show that crushed stone sand can completely replace desert sand as a fine aggregate in concrete mixtures to minimise mechanical properties limitations caused by recycled aggregates. To the best of the knowledge of the author after referring to available database of research of the subject, it was found that no investigation has been carried out to produce RAC with $100 \%$ replacement of RA in place of GA. The use of RA in combination with FA and SF produced sustainable concrete.

\section{Materials and Methods}

\section{Materials:}

Cement:

Cement must be tested in a laboratory to ensure that it meets Indian Standards for quality. OPC 53 grade cement was used, which complied with IS:12269-1987. The brand used in this experimental work was MAHA Gold OPC 53 obtained from Visakhapatnam.
Chemical and physical properties of the cement were determined in accordance with IS: 4031-1985 and IS: 4031-1988. OPC 53 Grade cement must meet BIS specification IS: $12269-1987$, with a designed strength of at least $53 \mathrm{MPa}$ or $530 \mathrm{~kg} / \mathrm{cm} 2$ for 28 days [11]. Table 1 lists the characteristics of cement.

Table 1. Properties of Cement

\begin{tabular}{|c|c|c|c|}
\hline \multicolumn{2}{|c|}{ Property } & \multicolumn{2}{|c|}{ Test Results } \\
\hline \multicolumn{2}{|c|}{ Specific Gravity. } & \multicolumn{2}{|c|}{3.15} \\
\hline \multicolumn{2}{|c|}{ Fineness. } & \multicolumn{2}{|c|}{$8.23 \%$} \\
\hline \multicolumn{2}{|c|}{ Normal Consistency. } & \multicolumn{2}{|c|}{$33 \%$} \\
\hline \multirow{2}{*}{ Setting time } & Initial & \multicolumn{2}{|c|}{110 minutes } \\
\hline & Final & \multicolumn{2}{|c|}{600 minutes } \\
\hline \multirow{3}{*}{\multicolumn{2}{|c|}{ Compressive strength }} & 3 days & $24.57 \mathrm{MPa}$ \\
\hline & & 7 days & $38.10 \mathrm{MPa}$ \\
\hline & & 28 days & $53.16 \mathrm{MPa}$ \\
\hline
\end{tabular}

Fine Aggregate:

Depending on the application, fine aggregate and coarse sand are made from natural sand, crushed stone, or gravel stone dust. It should be able to pass through the $4.75 \mathrm{~mm}$ diameter I.S. Sieve. With a maximum silt content of $4 \%$, the fineness modulus should be between 2.50 and 3.50 . Natural river sand was used in the experiment as the coarse sand.

When natural sand is unavailable, crushed stone is commonly used as a fine aggregate. According to IS $383-1970$, the fine aggregate used in this study is classified as Zone - II. Table 2 lists the properties of fine aggregates.

Table 2. Properties of Fine Aggregate

\begin{tabular}{|c|c|}
\hline Properties. & Test Results \\
\hline Specific gravity.(SG) & 2.5019 \\
\hline Water absorption. & $0.47 \%$ \\
\hline Fineness modulus & 3.18 \\
\hline
\end{tabular}

Granite Aggregate:

Aggregates which retain on the $4.75 \mathrm{~mm}$ IS sieve are called as coarse aggregates. The role of coarse aggregate in concrete is to act as a primary load-bearing component. According to IS 383 - 1970, coarse aggregate used in this present study is confirmed to be single-sized aggregate [12]. The present study used locally available granite aggregate (GA) with a maximum size of $20 \mathrm{~mm}$. It is important to test the quality of aggregates being used in the concrete for the further experimental testing procedures because aggregates occupy the major volume (75-80\% of total volume) in the concrete mix. Table 3 lists the characteristics of granite aggregate. 
Table 3. Properties of granite aggregate

\begin{tabular}{|c|c|}
\hline Properties & Test Values \\
\hline \multirow{2}{*}{ Specific gravity } & $20 \mathrm{~mm}-2.75$ \\
& $10 \mathrm{~mm}-2.65$ \\
\hline \multirow{2}{*}{ Water absorption } & $20 \mathrm{~mm}-0.3 \%$ \\
& $10 \mathrm{~mm}-0.5 \%$ \\
\hline \multirow{2}{*}{ Bulk density } & $20 \mathrm{~mm}-1.603$ \\
& $10 \mathrm{~mm}-1.510$ \\
\hline
\end{tabular}

Fly Ash (FA):

FA is a fine-grained substance made up primarily of spherical, glassy particles. It is produced as a by-product of the combustion of pulverized coal in a thermal power plant. The use of fly ash in concrete has a number of advantages, including improved workability, durability, and a reduction in the heat of hydration during the curing process.

FA serves as both a fine aggregate and a cementitious component in the composite concrete mass. It affects the rheological properties of fresh concrete as well as the hardened concrete mass's strength, finish, porosity, and durability of the hardened concrete mass.

Fly ash is divided into two categories:

- Class C, which is usually made of lignite or sub-bituminous coal.

- Bituminous coals are used to make Class F.

Sub-bituminous coal fly ash contains more calcium and less iron than bituminous coal fly ash. The Simhadri NTPC thermal power plant in Visakhapatnam provided the fly ash used in the experiment. Tables 4 and 5 show the physical properties and chemical composition of FA.

Table 4. Physical Properties of FA

\begin{tabular}{|c|c|}
\hline Property & Test Results \\
\hline Specific gravity & 1.9 \\
\hline $\begin{array}{c}\text { Fineness } \\
(\% \text { retained on } 45 \mu \mathrm{m} \text { sieve })\end{array}$ & 33.2 \\
\hline
\end{tabular}

Table 5. Chemical composition of FA

\begin{tabular}{|l|c|}
\hline Chemical compositions & Test Results (\%) \\
\hline$\left(\mathrm{SiO}_{2}\right)+\left(\mathrm{Al}_{2} \mathrm{O}_{3}\right)+\left(\mathrm{Fe}_{2} \mathrm{O}_{3}\right)$ & 70 \\
\hline Silicon Dioxide & 35 \\
\hline Reactive silica & 20 \\
\hline Magnesium Oxide $(\mathrm{MgO})$ & 5.0 \\
\hline Sulphuric trioxide $\left(\mathrm{SO}_{3}\right)$ & 3.0 \\
\hline Sodium oxide $\left(\mathrm{Na}_{2} \mathrm{O}_{3}\right)$ & 1.5 \\
\hline Total chlorides & 0.05 \\
\hline Loss on ignition & 5 \\
\hline
\end{tabular}

Silica Fume (SF):

Micro silica, or silica fume, is a non-crystalline silicon dioxide material. It is produced as a byproduct in the production of silicon and ferrosilicon alloys, and it is composed of spherical particles with an average particle diameter of $150 \mathrm{~nm}$ on the surface. Silica fume is an ultrafine powder which improves bonding within the concrete. Silica fume reduces the permeability and increases the durability, the compressive and flexural strength. Silica fume used in experimental work was obtained from local industries near autonagar, Visakhapatnam. The physical properties and chemical composition of SF are presented in Tables 6 and 7.

Tables 6. Physical properties of SF

\begin{tabular}{|c|c|}
\hline Property & Test Results \\
\hline Specific gravity & 2.29 \\
\hline Fineness (\%) & 4.50 \\
\hline
\end{tabular}

Table 7. Chemical composition of SF

\begin{tabular}{|c|c|}
\hline Chemical compositions & Test Results (\%) \\
\hline Silica dioxide $\left(\mathrm{SiO}_{2}\right)$ & 85 \\
\hline Moisture content & 3 \\
\hline Cao content & $<1$ \\
\hline Alkalis as $\mathrm{Na}_{2} \mathrm{O}$ & 1.5 \\
\hline Loss on ignition & 4.0 \\
\hline
\end{tabular}

Recycled Aggregate (RA):

The GAC cubes were crushed in a jaw crusher to produce $20 \mathrm{~mm}$ and $10 \mathrm{~mm}$ RA. Recycled aggregates RA30, RA35 and RA40 are derived from granite aggregate concretes GAC30, GAC35 and GAC40, respectively. The properties of RA were presented in table 8. When RA is used in untreated condition, it absorbs more water which affects the hydration. Hence, RA was pre saturated and used in surface dry condition before it is mixed.

Table 8. Properties of recycled Aggregate

\begin{tabular}{|l|c|c|c|}
\hline Properties & RA 30 & RA 35 & RA 40 \\
\hline Specific Gravity(SG) & 2.69 & 2.67 & 2.65 \\
\hline Water absorption & $3.23 \%$ & $3.27 \%$ & $3.31 \%$ \\
\hline Aggregate Impact Value & 24.92 & 24.79 & 21.64 \\
\hline Aggregate crushing value & 27.55 & 26.49 & 26.45 \\
\hline Flakiness Index & 14.19 & 14.21 & 14.70 \\
\hline Fineness Modulus & 6.979 & 6.954 & 6.898 \\
\hline
\end{tabular}

\section{Mix Proportions:}

Mix Proportions of GAC

The design mix for granite aggregate concrete GAC30, GAC35 and GAC 40 grades of concrete was carried out as per IS 10262-2009.

\section{Preparation of Recycled Aggregate Concrete (RAC):}

Three-stage mixing approach is used for preparation of RAC. RAC 30 is produced by replacing $100 \%$ of GA with 
RA30, RA35 and RA40 in GAC 30 grade concrete. The cement is also replaced partially with pozzolanic materials i.e, FA and $\mathrm{SF}$ at $20 \%$ and $10 \%$ respectively.

\section{Results and Discussions}

\subsection{Workability}

The consistency of concrete is determined by the workability test. It's used to test the consistency of newly poured concrete. The ease with which concrete flows is referred to as consistency. Concrete workability is affected by consistency; wetter mixes are more workable than drier mixes. The Slump Cone test apparatus is a commonly used method of determining the workability of newly mixed concrete. The slump test has a $300 \mathrm{~mm}$ height and is shaped like a frustum of a cone. The base has a diameter of $200 \mathrm{~mm}$ and a top opening of $100 \mathrm{~mm}$. Three layers of concrete are poured into the container, each of which is tested for workability. The container is filled with concrete in three layers, each of which is tested for workability before being placed on a smooth surface. The slump test is performed according to IS 1199-1959 after the concrete has been batched.

Here, Slump cone test is performed on RAC concrete as per IS 1199-1959 to measure the workability. Figure 1 shows the variation of workability with the grade of parent concrete. The slump of RAC is less compared to that of GAC. It can be observed that the slump decreases with the increase in grade of parent concrete because adhered mortar of higher-grade parent concrete absorbs more water because the mix is richer.

\subsection{Density}

Density of concrete is a measurement of its unit weight. The density of concrete is determined by the aggregate density, entrained air, water content, and cement content. Figure 2 shows how the density of RAC varies depending on the parent concrete grade. The RAC density is found to be lower than that of the GAC. This is in line with findings of T.Manikandan et al. . [3]. The density of the parent concrete also decreased as the grade increased. This could be because recycled aggregate has a lower density than granite aggregate.

\subsection{Water Absorption}

The percentage of water absorbed by the concrete is determined by a water absorption test. The cube specimens are taken out of the curing tank after 28 days of curing and weighed accurately and noted as saturated weight. The ratio of the difference between the initial weight of the specimen before immersing in curing tank and the saturated weight multiplied by 100 gives water absorption . Fig. 3 shows the variation of water absorption with the grade of parent concrete. The water absorption is more in RAC than that of GAC. This is in line with findings of T. Manikandan et al. [3]. This increased water absorption could result from adhered mortar. As the grade of parent concrete increased, the water absorption also increased due to the higher absorption by rich adhered mortar of higher-grade parent concrete.

\subsection{Compressive Strength}

Recycled concrete mixes made entirely of recycled aggregates $(100 \%)$ were tested at 7 and 28 days, in accordance with IS $516-1959$. [13]. Figure 4 depicts the relationship between the compressive strength of RAC and the grade of parent concrete. RAC concrete could not achieve the same strength as that of GAC at early ages due to the delayed setting time caused by the pozzolana. It was observed from Fig 4 that the grade of parent concrete influenced the strength of RAC. RAC 30 prepared with pozzolana $(20 \% \mathrm{FA}$ and $10 \% \mathrm{SF})$ and recycled aggregate of grade equal or higher than RA30 exhibited more or less the desired target strength of GAC i.e., 38MPa. This is in agreement with the findings of Valeria Corinaldesi [5] that mineral admixtures contributed to higher compressive strength. This may be attributed to the fact that the increased density of RAC with the increased grade of parent concrete results in higher packing of materials. 


\section{Workability of Recycled Aggregate Concrete}

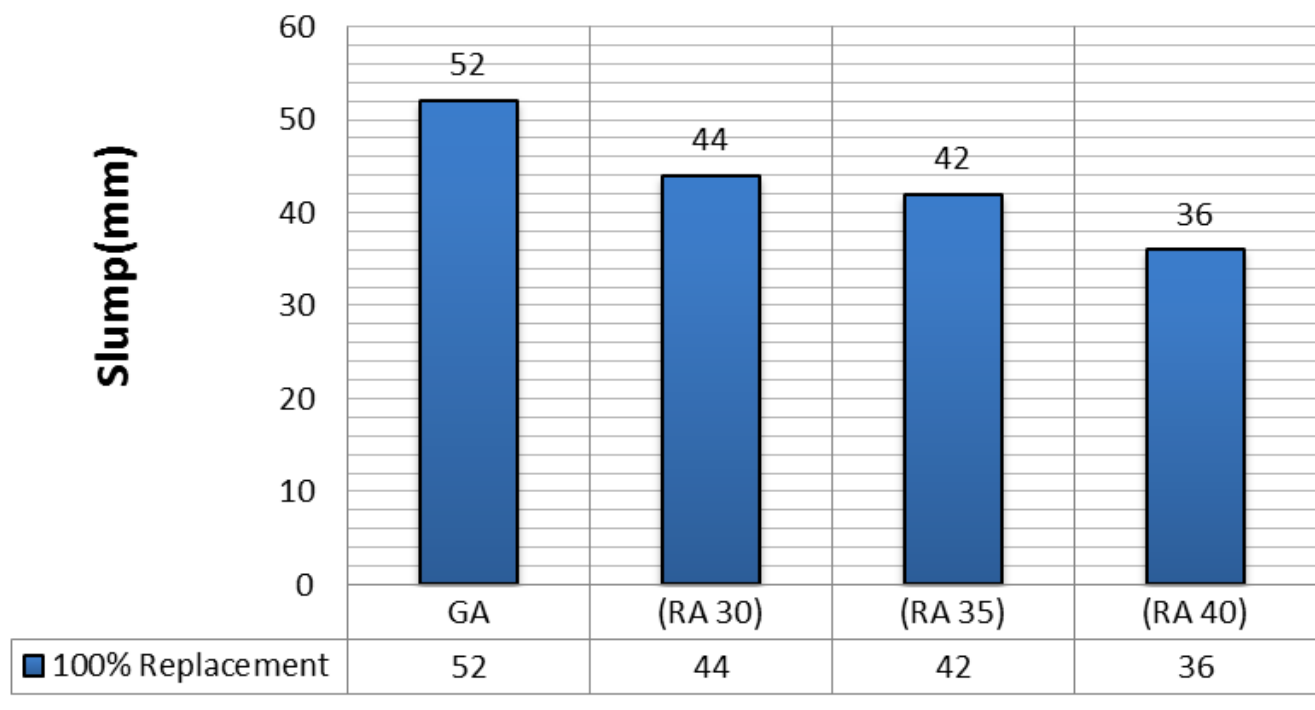

Figure 1. Slump of RAC with grade of parent concrete

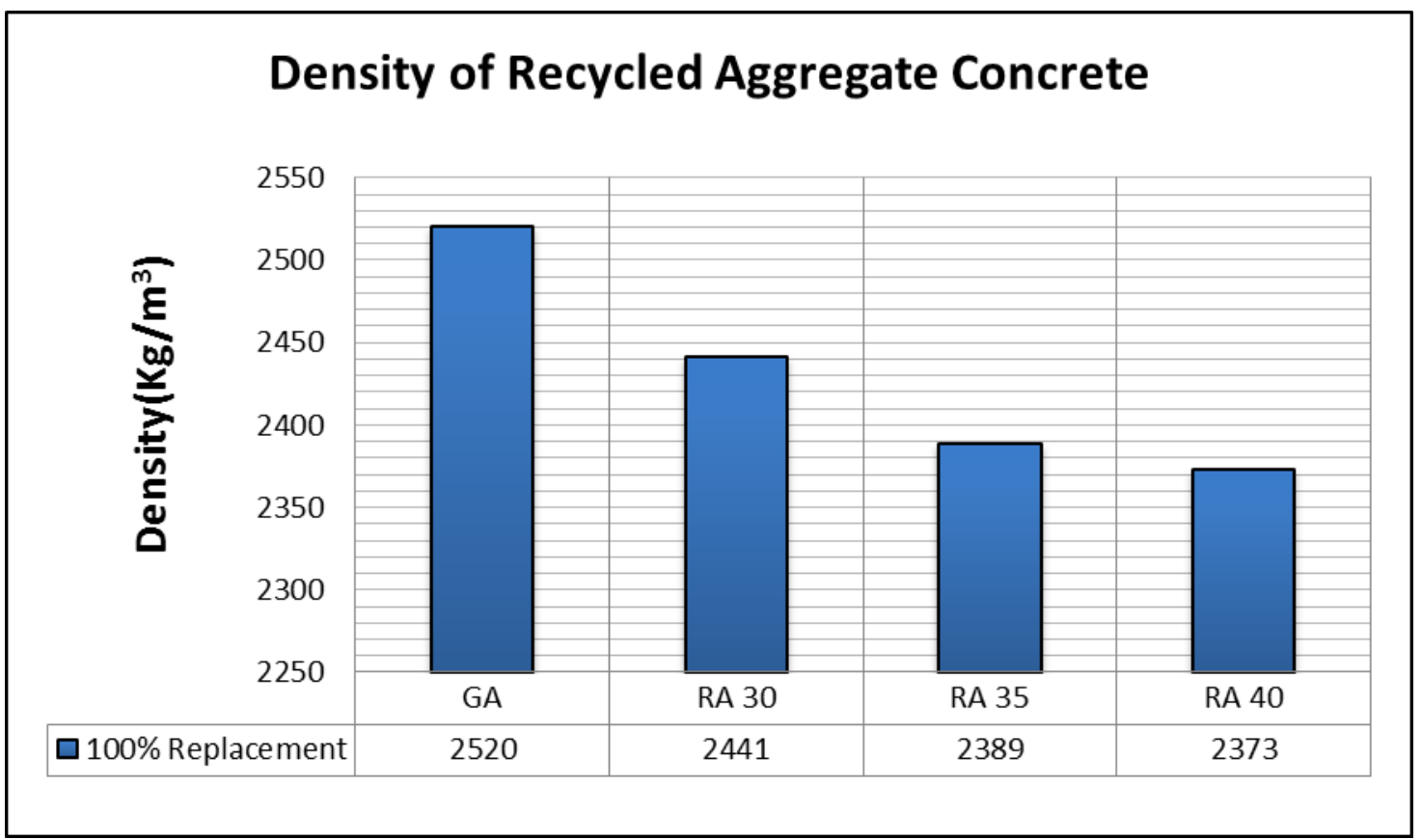

Figure 2. Density of RAC with grade of parent concrete 


\section{Water Absorption of Reccyled Aggregate Concrete}

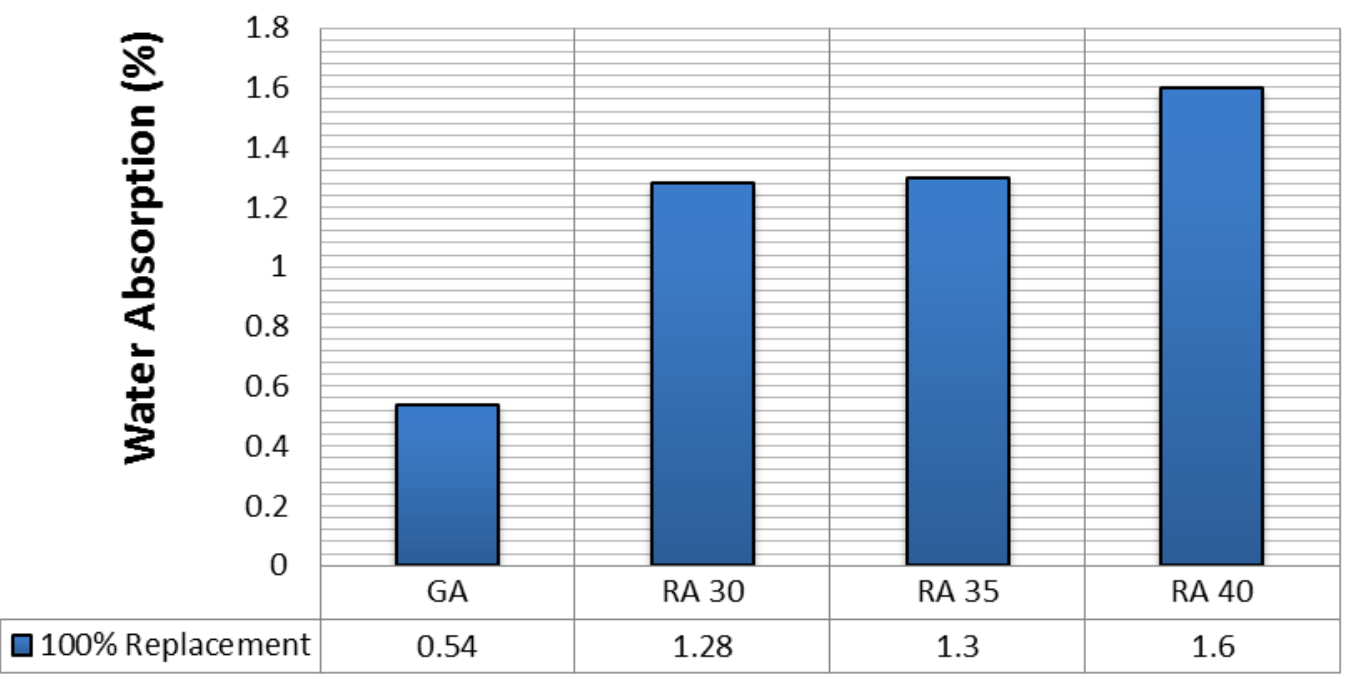

Figure 3. Water absorption of RAC with grade of parent concrete

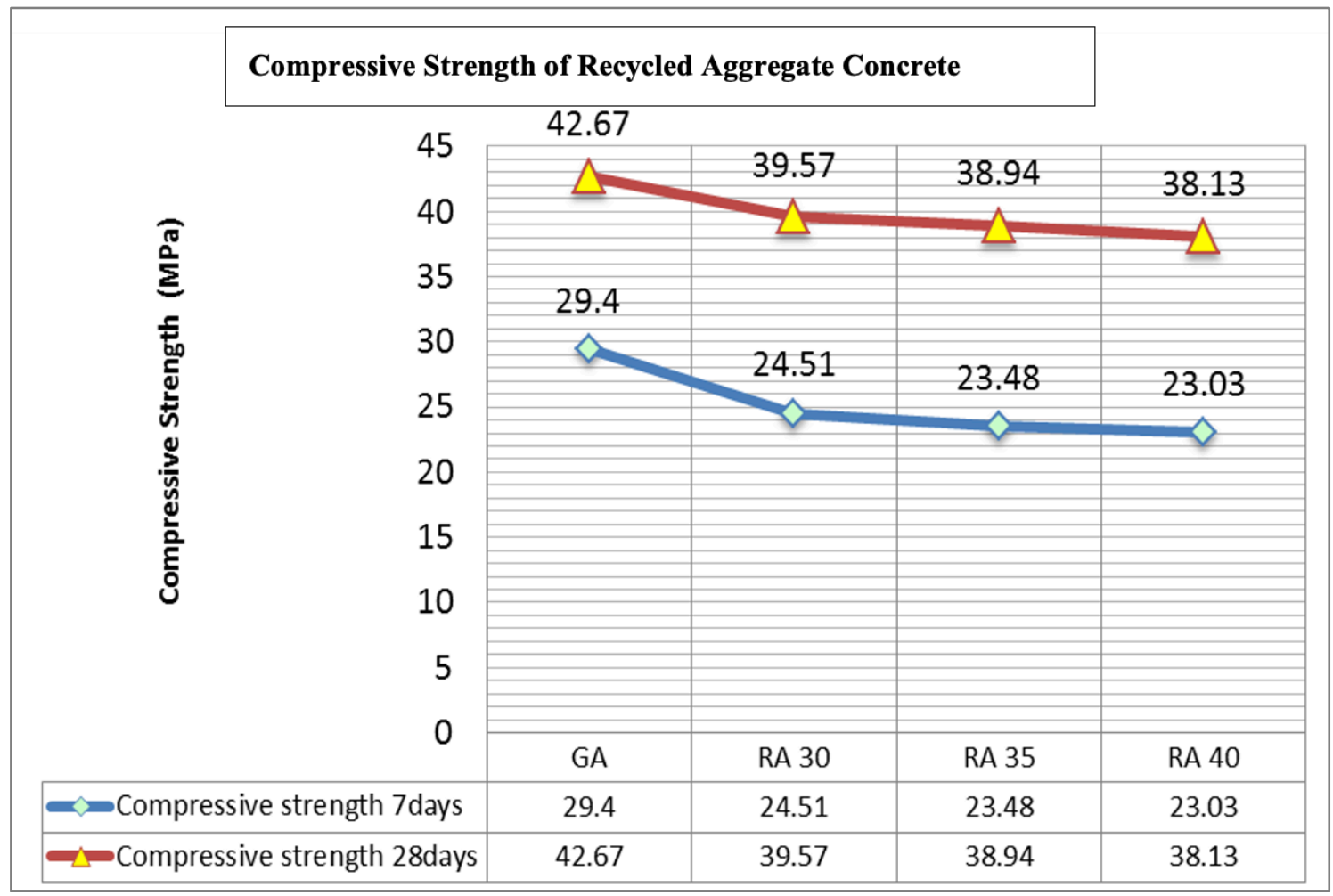

Figure 4. Compressive strength of RAC with grade of parent concrete

Table 9. Mix Proportions of GAC

\begin{tabular}{|c|c|c|c|c|c|c|}
\hline Grade of concrete & $\begin{array}{c}\text { Cement (OPC 53) } \\
\left(\mathrm{Kg} / \mathrm{m}^{3}\right)\end{array}$ & $\begin{array}{c}\text { Sand } \\
\left(\mathrm{Kg} / \mathrm{m}^{3}\right)\end{array}$ & $\mathrm{GA}\left(\mathrm{Kg} / \mathrm{m}^{3}\right)$ & $\begin{array}{c}\text { Water } \\
\left(\mathrm{Kg} / \mathrm{m}^{3}\right)\end{array}$ & $\mathrm{W} / \mathrm{c}$ ratio & $\begin{array}{c}\text { Target strength } \\
(\mathrm{MPa})\end{array}$ \\
\hline GAC30 & 330 & 725 & 1242 & 148.5 & 0.45 & 38 \\
\hline GAC35 & 360 & 702 & 1200 & 162 & 0.45 & 43 \\
\hline GAC40 & 380 & 681 & 1220 & 152 & 0.40 & 51 \\
\hline
\end{tabular}




\section{Conclusions}

It is feasible to replace the Granite aggregates (GA) with (RA) without compromising the desirable properties. The physical \& mechanical properties such as the bulk density, fineness modulus, impact value ,crushing value,flakiness and elongation indices of the RA confirms the limits specified in IS 383-1972. The amount of mortar adhered to the RA increased as the parent concrete grade increased as the rich concrete mixes comprise of higher cement content. The slump of RAC is less compared to that of GAC. The slump of RAC decreased with the richness in grade of parent concrete.

The density of the RAC is less than that of the GAC. Richer is the grade of parent concrete, lesser is the density. As the richness of parent concrete increased, the water absorption also increased due to the higher absorption of rich adhered mortar. The replacement of cement with FA and SF up to a total of $30 \%$ contributes to a highly sustainable concrete.

RAC could not achieve the same strength as GAC at early ages i.e at 7days. The desired target strength was achieved by RAC prepared with pozzolana $(20 \% \mathrm{FA}$ and $10 \% \mathrm{SF}$ ) and $100 \%$ recycled aggregate of grade equal or higher than RA30.Within the limits of experimental investigations, a highly sustainable RA 30 grade concrete was produced by replacing the GA completely with RA of same grade parent concrete and with the use of combination of $20 \%$ Flyash \& $10 \%$ Silica Fume.

\section{REFERENCES}

[1] Zhang, J., Shi, Li, Y Pan, X., Poon, C, Xie Z, "Performance Enhancement of Recycled Concrete Aggregates through Carbonation", American Society of Civil Engineers 2015, Volume 27, (2015), pp. 04015029 - (1-6), 2015.

[2] Mmasetlhomo Tommy Gumede, Shodolapo Oluyemi Franklin, "Studies on Strength and Related Properties of Concrete Incorporating Aggregates from Demolished
Wastes", Open Journal of Civil Engineering, Volume 5, pp.175-184, 2015.

[3] T. Manikandan, M. Mohan, Y.M. Siddaharamaiah, "International Journal of Innovative Science", Engineering \& Technology, Vol. 2. Pp.438-441, 2015

[4] Sudhir P. Patil, Ganesh Single, Prashant D. Sathe, "Recycled Coarse Aggregates" International Journal of Advanced Technology in Civil Engineering, ISSN: 2231 5721, Volume-2, 2013

[5] Valeria Corinaldesi and Giacomo Moriconi., "Influence of mineral additions on the performance of $100 \%$ recycled aggregate concrete", Construction and building materials, vol-23, pp 2869-2876, 2009.

[6] S C. Kou and C.S. Poon., "Enhancing the durability properties of concrete prepared with coarse recycled aggregate", Construction and building materials, Vol-35, pp.69-76, 2012.

[7] Shi Cong Kou, Chi Sun Poon and Dixon Chan., "Influence of fly ash as a cement addition on the hardened properties of recycled aggregate concrete", Materials and structures, Vol-41, pp.1191-1201, 2008

[8] Valeria Corinaldesi, "Study of the Mechanical and elastic behaviour of concretes made of recycled-concrete coarse aggregates", Science Direct, Vol 24, pp.1616-1620, 2010.

[9] Walid Fouad Edris, Essam Odah, Isam Abu-Qasmieh, Amany Hendy, "Mechanical Properties of Translucent Concrete Using Plexiglass Bars and Fiberglass," Civil Engineering and Architecture, Vol. 9, No. 2, pp. 293 - 300, 2021. DOI: $10.13189 /$ cea.2021.090203.

[10] Roz-Ud-Din Nassar, "Characteristics of Recycled Aggregate Concrete Produced with Crushed Stone Sand as Fine Aggregate", Civil Engineering and Architecture, Vol. 8, No. 4, pp. 632- 640, 2020. DOI: $10.13189 /$ cea.2020.080426.

[11] IS:12269-1987 Specifications for 53 Grade Ordinary Portland Cement.

[12] IS: 383- 1970 Specification for Coarse and fine aggregates from natural sources for concrete.

[13] IS: 516 -1959 Method of test for strength of concrete (sixth print January 1976). 